\title{
As (re)configurações do campo jurídico e sua relação com a mídia na sociedade contemporânea
}

The (re)cofigurations of the judicial field and its relation with the media on contemporary society

\author{
Charlene DALCOL \\ Doutoranda no Programa de Pós-Graduação em Comunicação da \\ Universidade Federal de Santa Maria (UFSM) \\ charlenedalcol@gmail.com \\ https://orcid.org/0000-0002-0982-4116 (잉
}

Maria Ivete Trevisan FOSSÁ

Doutora em Administração pela Universidade Federal do Rio Grande do Sul (UFRGS).

Professora Associada nível II do Departamento de Ciências da Comunicação da Universidade Federal de Santa Maria (UFSM).

fossa@terra.com.br

https://orcid.org/0000-0001-6536-6714 (잉

Mais informações da obra no final do artigo

\section{RESUMO}

Este artigo promove uma reflexão teórica acerca das (re)configurações do campo jurídico e suas movimentações na sociedade contemporânea, colocando-as à luz dos processos de midiatização. Nossa ênfase é na relação de entrelaçamento entre o campo jurídico e o midiático, que acaba contribuindo para uma atuação espetacular da Justiça. Assumimos a pesquisa bibliográfica como metodologia para encontrar indícios que nos levem à reflexão, interpretação e tensionamento dos conceitos propostos pelos autores. Observamos, portanto, que as (re)configurações observadas nos movimentados do campo jurídico têm relação direta com o entrelaçamento do campo midiático e, da própria mídia, a este campo organizando um verdadeiro palco de visibilidade pública do judiciário.

PALAVRAS-CHAVE: Campos Sociais; Campo Jurídico; Campo Midiático; Mídia.

\begin{abstract}
This article promotes a theoretical reflection about the (re) configurations of the legal field and its movements in contemporary society, placing them in the light of the processes of mediatization. Our emphasis is on the intertwining relationship between the legal and media fields, which ultimately contributes to a spectacular performance of justice. We assume bibliographical research as a methodology to find indications that lead us to the reflection, interpretation and tension of the concepts proposed by the authors. We observed, therefore, that the (re)configurations observed in those in the legal field are directly related to the interweaving of the media field and, from the media itself, to this field, organizing a real stage of public visibility of the judiciary.

KEYWORDS: Social Fields; Legal Field; Media Field; Media.
\end{abstract}




\section{Considerações Iniciais}

As democracias contemporâneas estão, cada vez mais, influenciadas pela presença e atuação dos meios de comunicação. A mídia se apresenta como um elemento fundamental dos processos democráticos e condição sine qua non para os movimentos dos diversos campos sociais. Estamos assistindo ao que se denomina como a "midiatização da sociedade", ou seja, o acesso às linguagens e tecnologias utilizadas pela mídia se tornaram indispensáveis para os fazeres dos mais diversos campos e atores sociais.

Dentro deste processo de midiatização, o campo midiático apresenta-se como um verdadeiro espaço de intercâmbio de demandas da sociedade que provocam o debate público e (re)organizam os processos sociais. Confirmamos o pensamento de Braga (2011) quando diz que a midiatização é um processo comunicacional da sociedade, muito mais do que uma "ação das mídias" sobre a sociedade.

Com este breve pano de fundo, este artigo, de cunho teórico, promove uma reflexão acerca das (re)configurações do campo jurídico e suas movimentações na sociedade contemporânea, colocando-as à luz dos processos de midiatização. A questão que move o desenvolvimento desta reflexão passa pelo aspecto transformador da comunicação (BRAGA, 2013), considerando que refletiremos sobre as transformações acionadas pelo processo comunicacional sob o ponto de vista teórico-reflexivo.

Partimos da perspectiva bourdiana (teoria dos campos) que vê a ideia de "campo", como espaço de disputas de poder entre grupos. Segundo Bourdieu, as necessidades dos agentes e o choque de interesses específicos entre os atores são definidos no "campo", onde se desenvolvem as estratégias nas relações de poder. Martino (2003) diz que a noção de campo pode ser entendida como um espaço estruturado de posições, ocupadas por agentes em competição, sendo que sua lógica independe desses agentes. Para o autor, o campo se define primeiramente como lugar abstrato onde age o pessoal especializado no jogo pela conquista da hegemonia.

Nossa ênfase é na relação de entrelaçamento entre o campo jurídico e o midiático, que acaba contribuindo, entre outros elementos, para uma atuação espetacular da Justiça. Sfez (1992) aponta que já não são os políticos e os governos os detentores da verdade, mas sim o aparelho de comunicação em aliança com o aparelho da Justiça. $O$ campo jurídico, a nosso ver, tornou-se um lugar de relações de poder, onde seus agentes 
usam a mídia a serviço de seus próprios interesses e se colocam na posição de "portadores de verdades e valores transcendentais e universais" (BOURDIEU, 1986). O campo midiático apresenta-se, então, como hegemônico, promovendo a publicitação, estimulando o debate e conferindo visibilidade pública aos atos de poder da Justiça.

Para este estudo, partimos da ideia de que o campo jurídico tem uma dinâmica própria e se conecta diretamente com outros campos de poder, na mesma medida em que está carregado de estratégias de dominação impostas pelos meios institucionais. Logo, entendemos ser de fundamental importância a compreensão e o entendimento da ideia de campo e a noção de habitus, estreitamente ligadas ao modus operandi, definidos por Pierre Bourdieu. Portanto, entendemos, desde já, que o campo jurídico é possuidor de um habitus e não pode ser pensado como um universo autônomo de relações sociais; seria exatamente o contrário; ele é sempre possuidor de um modo de pensamento relacional.

Assumimos a pesquisa bibliográfica como metodologia para encontrar indícios que nos levem à reflexão, interpretação e tensionamento dos conceitos propostos pelos autores. Lakatos e Marconi (2006) apontam que o aprofundamento bibliográfico é um procedimento sistemático, reflexivo e interpretativo, controlado e crítico, que permite encontrar novos conteúdos situados em diferenciadas áreas.

Este artigo está organizado em três momentos. Inicialmente, retoma breves apontamentos sobre a midiatização da sociedade com base em Sodré (2002), Fausto Neto (2006) e Braga (2011). No segundo momento, são abordados alguns dos principais pontos que configuram o campo midiático como espaço de visibilidade pública da Justiça, apoiando-nos em Rodrigues (1997), Thompson (2008) e Silverstone (2003). O último tópico aborda as (re)configurações do campo jurídico à luz da mídia, com base nas ideias de Bourdieu (2000) e Bourdieu e Teubner (2000).

Cabe ressaltar que o objetivo central da reflexão proposta passa também por realizar uma breve aproximação com as teorias que envolvem a Tese de Doutorado em andamento ${ }^{1}$. Antes de ser um ponto de chegada, este artigo pretende apresentar um caminho, um percurso para uma pesquisa mais aprofundada e ampla sobre a temática.

Faz-se necessária, também, uma colocação acerca do envolvimento deste estudo com o campo do Direito. Apesar da partilha de reflexões, conceitos e considerações, o

\footnotetext{
${ }^{1} \mathrm{O}$ tema central da referida Tese envolve questões referentes à compreensão do caráter estratégico da publicização da informação de interesse público como dinamizador do processo de visibilidade institucional do Ministério Público Federal (MPF) no Caso Lava Jato, e o trabalho está inserido no Grupo de Pesquisa "Comunicação Institucional e Organizacional" da UFSM, registrado no CNPq.
} 
objetivo será de evitar especificações e buscar apenas contextualizar as possibilidades de interação comunicacional na atualidade. Acompanhamos a ideia de interdisciplinaridade, proposta por Braga (2011), considerando a reflexão proposta como uma interface com os estudos do Direito e das Ciências Sociais e um espaço de trabalho constitutivo do conhecimento comunicacional.

\section{Breves apontamentos sobre a midiatização da sociedade}

Vivemos em uma sociedade em franca transformação, por isso faz-se necessário observar as configurações sociais em que todos os campos estão inseridos. Com a introdução da tecnologia da informação e da comunicação, estamos assistindo a uma nova configuração social. A sociedade encontra-se em processo de midiatização (FAUSTO NETO, 2007; SODRÉ, 2002).

Na busca por uma melhor compreensão de como a mídia se difunde e influencia outros campos sociais e instituições, o estudo dos conceitos de midiatização é indispensável, uma vez que a mídia não pode mais ser considerada como algo separado das instituições sociais já que a sociedade é permeada pela lógica midiática. Pérsigo e Fossá (2010) apontam para o fato de que a midiatização é um conceito ainda em formação, pouco problematizado no campo da comunicação. Ao mesmo tempo, seu estudo se torna importante devido ao fato de a tecnologia se inserir em toda sociedade, sendo também um processo fruto da complexificação dos processos midiáticos.

Não é mais novidade que a sociedade é midiatizada e o que importa para o contexto desse artigo é tentar observar a tecnologia midiática a partir de suas incursões nas relações entre atores e campos sociais e a repercussão disso no campo midiático. Nosso interesse pelos estudos da midiatização se faz pelo seu enfoque sobre o papel da mídia na transformação das relações sociais e culturais (HJARVARD, 2014).

Somando-se a esta primeira ideia, acompanhamos o raciocínio de Sgorla (2009, p. 61) que pontua que o estudo dos processos de midiatização se justifica pela "necessidade iminente de desvendar as dinâmicas consequentes das incursões das tecnologias midiáticas, transformadas, agora, em mídias propriamente, nas práticas e nas relações sociais, nos processos midiáticos e na sociedade contemporânea”.

Nesta órbita, há que se evitar uma possível confusão entre os conceitos de midiatização, mediação e interação, conforme alerta Sodré (2002). Para o autor, mediar é 
"fazer ponte", fazer comunicarem-se duas partes com diferentes tipos de interação. "Já a midiatização é uma ordem de mediações socialmente realizadas no sentido da comunicação entendida como processo informacional” (SODRÉ, 2002, p. 21). O mesmo autor explica que a midiatização caracteriza outra etapa cultural, onde a comunicação se centra na informação, constituindo uma nova "tecnologia societal". Surge, então, uma diferente forma de o sujeito estar no mundo, uma qualificação particular de vida, o que Sodré (2002) intitula de bios específico. Sodré (2002, p. 21) conceitua a "midiatização" como

[...] uma ordem de mediações socialmente realizadas no sentido da comunicação entendida como processo informacional, a reboque de organizações empresariais e com ênfase num tipo particular de interação a que poderíamos chamar de 'tecno-interação' -, caracterizada por uma espécie de prótese tecnológica e mercadológica da realidade sensível, denominada medium.

Abrimos um parêntese para pontuar o conceito de mediação proposto por Barbero (1997). O autor, imbricado nas questões referentes ao uso social da mídia (especialmente a televisão), considera as mediações como lugares de onde provêm e onde se forma a sociabilidade e se expressa a cultura.

Segundo Fausto Neto (2006), a midiatização acontece em vários níveis da vida social, sendo o desenvolvimento de uma modalidade prática de comunicação que ainda requer leituras e interpretações. Para o autor, a midiatização se manifesta em vários níveis da vida social e se torna uma referência matricial.

Os campos sociais são vistos como autônomos, sendo que a regulação se dá entre dispositivos nomeados pelas instituições dispersas no tecido social. Não há um campo regulador específico. São formas de linguagens que se enquadram na nova ambiência, em decorrência do desenvolvimento de uma modalidade prática de comunicação que impõe, aos campos de conhecimento, demandas de leituras e de interpretações que superariam os protocolos clássicos. Na mesma direção, Fausto Neto (2006, p. 3) aponta que a "sociedade midiatizada" apresenta

[...] sua estrutura e dinâmica calcada na compressão espacial e temporal, que não somente institui, como faz funcionar um novo tipo de real, cuja base das interações sociais não mais se tecem e se estabelecem através de laços sociais, mas de ligações sociotécnicas. 
A sociedade midiatizada tem uma nova formação social e organizacional: linearidade transforma-se em descontinuidade, a comunicação homogênea é agora heterogênea e a ideia da sociedade uniforme pelos meios de comunicação teve que ser ratificada. Sem dúvida, há uma sociedade mais complexa, onde a lógica dos fluxos ganha destaque. Há um novo jeito de se pensar e viver o vínculo social, onde os laços sociais passam a ser laços sócio-técnicos. Segundo Fausto Neto (2006, p. 04)

[...] ao invés do ato social, a rede. Do vínculo, ao fluxo. Do contrato social, à terceirização generalizada. Referências fundacionais são mandadas para os ares, consequências da lógica reinante da sociedade segundo a qual 'vivemos no ar' [...] mudam as relações pessoais e familiares. Terceiriza-se a função do autor [...]. E também à própria reflexividade, hoje transferida aos modernos narradores, os dispositivos midiáticos [...]. As lutas já não têm como meta velhas teleologias morais, éticas, confessionais e políticas $[\ldots]$.

Braga (2011, p. 70) entende que

[...] a midiatização como um conjunto complexo de ações de sociedade (incluindo aí, é claro, a organização empresarial e o desenvolvimento tecnológico) que crescentemente se estabelecem como processo interacional de referência, passando a abranger e direcionar processos gerais anteriores: os da escrita, que anteriormente (e ainda) se apresenta como processo de referência principal, subsumindo a generalidade de processos; e os da oralidade tradicional.

Para o autor, a sociedade midiatizada não é uma "consequência" dos dispositivos técnicos de mídia, mas é a própria sociedade que gera essa necessidade, tratando-se da origem e desenvolvimento destas tecnologias midiáticas.

[...] é porque a sociedade crescentemente gerou a necessidade, para processar suas interações, de comunicações mais amplas e abrangentes, mas específicas e especializadas, mais diversas, mais eficazes (etc.) que foi desenvolvendo mais e mais procedimentos e tecnologias mediáticas (BRAGA, 2004, p. 11).

Os malefícios desse processo são apresentando por Hjarvard (2014), quando registra que a midiatização tem complicado a distinção do que é real e o que é representação do midiático. Logo, a midiatização implica em uma transformação única da realidade mediada e, o que antes era experienciado, agora se dissolve. A sociedade se torna dependente da mídia e de sua lógica, em um processo de dualidade. Ou seja, os meios de comunicação (componentes do campo midiático) passaram a estar integrados às operações de outras instituições sociais e, por sua vez, também adquiriram o status de 
instituição. Assim, toda a interação entre sociedade, organizações e indivíduos acontece por intermédio dos meios de comunicação.

Os campos sociais usam a midiatização para construir suas estratégias e identidades. E, mais, as práticas de comunicação afetam o campo das mídias, quando o conteúdo é embasado em outros campos sociais, como, por exemplo, na mídia impressa e/ou quando o discurso jornalístico traz à tona questões que seriam da esfera privada.

Para compreender a importância da mídia na sociedade contemporânea se faz necessária uma atenção para as transformações estruturais dos meios de comunicação. Neste sentido, conforme Hjarvard (2014, p. 15), "os estudos de midiatização ocupam-se das mudanças estruturais de longo prazo relativas ao papel da mídia na cultura e na sociedade, em que os meios de comunicação adquirem maior autoridade para definir a realidade e os padrões de interação social".

A sociedade se tornou midiatizada e "a midiatização pode ser considerada um processo macrossocial, na medida em que suas influências se fazem visíveis na sociedade como um todo" (HJARVARD, 2014, p. 17). Thompson (1990) vê a midiatização como um elemento constitutivo do desenvolvimento da sociedade moderna. Para ele, há "uma forte ligação entre a midiatização, suas consequências culturais e o surgimento das grandes organizações de mídia em nível nacional e global".

Em que pese a midiatização não ter a pretensão de substituir as teorias da mídia e da comunicação, nossa imersão nos seus desdobramentos conceituais se dá na medida em que buscamos compreender as formas sociais e comunicativas desenvolvidas pelos campos sociais, em especial nas imbricações entre o campo jurídico e o midiático, quando os meios de comunicação e a própria mídia são utilizados nas interações sociais.

No tópico seguinte, apresentaremos um panorama do campo midiático e como ele acaba dilatando as possibilidades de exposição dos movimentos do campo jurídico.

\section{O campo midiático como espaço de visibilidade pública da Justiça}

Rodrigues (1997) apresenta em seus estudos uma perspectiva para o entendimento da configuração dos campos sociais. Segundo ele, um campo social é composto por atores sociais individuais/coletivos e comporta saberes específicos de uma determinada área do conhecimento. Aponta Rodrigues (1997, p. 143) que "um campo social constitui uma instituição social, uma esfera de legitimidade”. Já Sodré (2012) 
conceitua campo como um espaço social composto por relações objetivas entre agentes e instituições e destinado a legitimar cognitivamente as suas enunciações. "É de fato um universo separado, com suas próprias leis de funcionamento" (SODRÉ, 2012, p. 14).

Estas conceituações teóricas proporcionam valiosos insights para compreender os movimentos do campo midiático. Recorreremos, então, aos conceitos de Campo dos Media ou campo midiático ou campo das mídias que, para Rodrigues (1997), é composto pelos meios de comunicação e seus atores e se configura de maneira relativamente autônoma frente os demais campos. Usando as palavras do autor, o Campo dos Media é a

[...] instituição de mediação que se instaura na modernidade, abarcando, portanto, todos os dispositivos, formal e informalmente organizados, que têm como função compor os valores legítimos divergentes das instituições, que adquirem nas sociedades modernas 0 direito a mobilizarem autonomamente o espaço público, em ordem à persecução dos seus objetivos e ao respeito dos seus interesses (RODRIGUES, 1997, p. 152).

Por isso, por meio dos processos de mediação, o Campo dos Media organiza a vida coletiva e torna-se responsável pela produção de sentidos que circulam nas sociedades, solidificando a própria realidade social.

O campo midiático tem por característica uma legitimidade que é, por natureza, delegada de outros campos da sociedade, justamente por suas características de mediação. Ele tem ocupado um lugar estratégico na sociedade contemporânea uma vez que proporciona, através de procedimentos técnicos e da própria linguagem, a publicitação dos fazeres sociais, tornando-se um operador de visibilidade e circulação de informações junto a outros campos sociais. Para Thompson (2008), existe uma nova visibilidade propiciada pela mídia e que altera as maneiras de agir e interagir dos indivíduos. O campo de visão não está mais restrito às características espaciais e temporais, moldando-se em função das diferentes mídias. "O desenvolvimento das mídias comunicacionais fez nascer, assim, um novo tipo de visibilidade desespacializada que possibilitou uma forma íntima de apresentação pessoal” (THOMPSON, 2008, p. 24).

Sobre a mídia, Fossá e Kegler (2008, p. 252) apontam que "é um processo complexo que interfere na construção e na manutenção da sociedade, seja enquanto dispositivo técnico seja enquanto dispositivo de linguagem (dispositivo de enunciação)". Essa processualidade da mídia é apontada por Silverstone (2003) como ponto de partida dos estudos midiáticos. 
É preciso examinar a mídia como um processo, como uma coisa em curso e uma coisa feita, e uma coisa em curso e feita em todos os níveis, onde quer que as pessoas se congreguem no espaço real ou virtual, onde se comunicam, onde procuram persuadir, informar, entreter, educar, onde procuram, de múltiplas maneiras e com graus de sucesso variáveis, se conectar umas com as outras (SILVERSTONE, 2003, p. 55).

Os atores/instituições sociais possuem uma necessidade iminente de estarem visíveis na esfera social e os meios de comunicação, por sua vez, operam e articulam processos de produção, transmissão e recepção de mensagens que servem de suporte para exposição, circulação e negociação das demandas e processos dos vários campos sociais. Rodrigues (1997) aponta que o

[...] campo dos media é a designação que utilizamos para dar conta da instituição de mediação que se instaura na modernidade, abarcando, portanto, todos os dispositivos formal e informalmente organizados que têm como função compor os valores legítimos divergentes das instituições que adquirem nas sociedades modernas 0 direito de mobilizarem autonomamente o espaço público (RODRIGUES, 1997, p. 152).

O Campo dos Media é "a instituição que possui a competência legítima para criar, impor, manter, sancionar e restabelecer a hierarquia de valores, assim como o conjunto de regras adequadas a respeito desses valores" (RODRIGUES, 2000, p. 202).

A inserção de questões dos campos sociais no campo midiático promove relacionamentos, intercâmbios e interações e a mídia se configura, conforme Rodrigues (1997), como "esfera obrigatória da visibilidade e da notoriedade". Fausto Neto (2006, p. 23) corrobora com este pensando quando pontua que na sociedade midiática "os meios de comunicação se constituem em setores estratégicos, no âmago da vida e da dinâmica tensional dos campos sociais".

Não há mais como olhar para a sociedade sem perceber como a mídia se imbrica a ela. Dentre os vários campos sociais que coexistem na esfera social (político, econômico, saúde, educação), o campo jurídico tem tido papel de destaque na sociedade contemporânea justamente por este processo de imbricamento com o campo midiático. A mídia tem se tornado um elemento fundamental na construção social do campo jurídico, bem como nas suas (re)configurações. No momento que exerce a função de informar, somada a certa dramatização e interpretação dos acontecimentos jurídicos, a mídia acaba influenciando a percepção da opinião pública.

A mídia tornou-se um espaço de exposição de casos judiciais, tendo, agentes e instituições, adquirido grande visibilidade. Procurando compreender o campo midiático como espaço de visibilidade pública das ações e movimentos do campo jurídico, abrimos 
um parêntese para atentar aos escritos de John Thompson que oferecem subsídios para uma reflexão sobre os novos desdobramentos da sociedade contemporânea, cuja característica principal passa pela representação como lugar de visibilidade, significância, valorização da imagem e propagação do consumo.

Nesta lógica, a mídia, enquanto arena de visibilidade, abre espaço para que acontecimentos antes ocultos, ganhem novo status, como algo público (THOMPSON, 2008). Para o autor, com a mídia, o que "era invisível tornou-se evidente para conhecimento de todos" (THOMPSON, 2008, p. 16).

Pensar o contexto social em que, hoje, é relacioná-lo com a influência da mídia sobre os movimentos e interações da sociedade. A visibilidade passou a ser uma moeda de poder. No atual paradigma da visibilidade através da mídia, "é possível que poucos estejam visíveis para muitos, ou seja, aqueles que exercem o poder, mais do que aqueles sobre os quais o poder se aplica, é que estão sujeitos a um novo tipo de visibilidade" (THOMPSON, 2008, p. 27).

Nosso exemplo mais claro desse movimento é a atuação do Ministério Público Federal (MPF) no contexto da Operação Lava Jato. A instituição tem sido alvo de críticas de uma parcela de importantes juristas brasileiros e de parte da própria sociedade, uma vez que alguns de seus procuradores tornaram-se muito mais "visíveis" do que pareciam ser anteriormente. Aqui, a nosso ver, percebe-se, claramente, a visibilidade midiática proposta por Thompson (2008, p. 36) em que "aqueles que estão em posição de relevo na vida pública ou aspiram a uma se veem agindo em um ambiente de informação que é muito diferente do que existia há séculos atrás".

Desde que as investigações da Lava Jato descobriram um enorme escândalo de corrupção no País, a Justiça Federal e os procuradores da República, envolvidos no caso, têm usado a sua relação com a imprensa e a força da opinião pública para legitimar o seu trabalho, bem como obter modificações legislativas que auxiliam o desempenho de suas funções acusatórias. E o campo midiático tem se tornado o palco perfeito para a obtenção de decisões judiciais favoráveis, como também para tornar o MPF e os seus procuradores os grandes artífices de uma sociedade "purificada" e livre do mal.

Ao entrar em uma disputa de "verdade absoluta" sobre temas que são interesse público, a mídia proporciona credibilidade aos atores do campo jurídico e o interesse público acaba proporcionando reconhecimento, apoio e imagem pública favorável.

Vejamos a seguir alguns exemplos de matérias da grande mídia que assinalam essa questão. A Figura 1 apresenta reportagem do G1 do dia 15/09/2016. O texto tenta 
explicar a polêmica em torno da frase "não temos prova, mas temos convicção" que foi atribuída ao procurador Deltan Dallagnol, quando o mesmo apresentou a denúncia do MPF contra o ex-presidente Luiz Inácio Lula da Silva, a mulher dele, Marisa Letícia, e mais seis pessoas no âmbito da Lava Jato.

Vale lembrar que a denúncia foi apresentada pelo procurador Deltan Dallagnol, coordenador da força tarefa da Lava Jato e responsável pelos casos de primeira instância ao lado de mais 11 procuradores que, ao todo, já denunciaram mais de 240 pessoas, entre elas os maiores empreiteiros e políticos do país.

Em tese, é possível inferir que os enquadramentos impostos pela mídia em relação aos desdobramentos da Lava Jato tentam colocá-la como imparcial, sem vinculação partidária, traçando uma narrativa que evoca para um distanciamento entre o trabalho realizado pelo MPF e uma possível "perseguição" a qualquer um dos agentes políticos envolvidos direta e/ou indiretamente no caso.

Figura 1 - Lead de matéria que questiona o "discurso" da Justiça

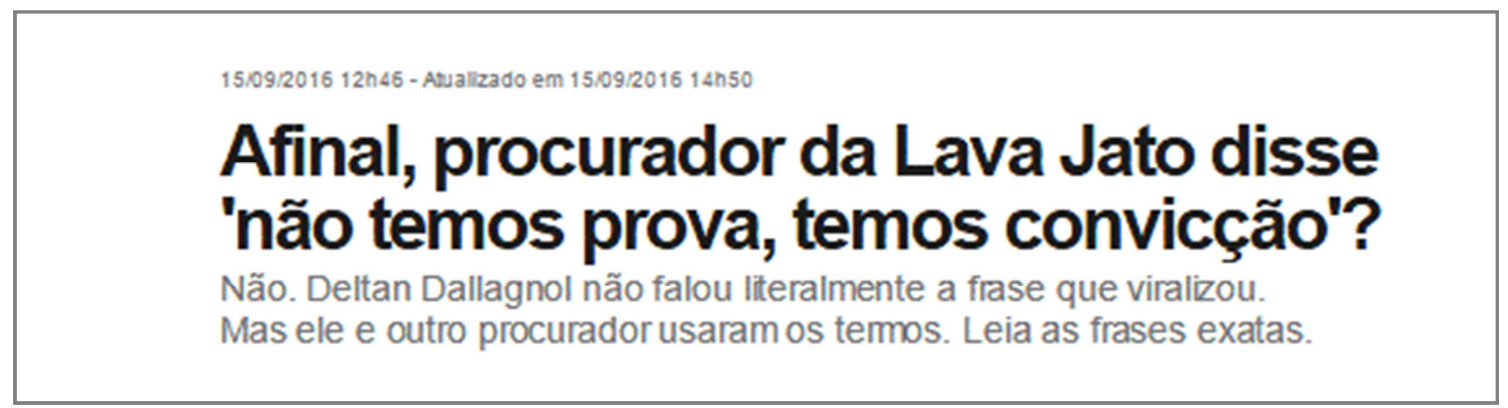

Fonte: G1

A Figura 2 exemplifica novamente a construção de um discurso legitimado por parte da Justiça. A matéria, da Carta Capital do dia 14/09/2016, traz à tona algumas falas do Procurador Deltan Dallagnol em uma tentativa de explicar o significado dos termos usados por ele mais uma vez, colocando em xeque o discurso jurídico construído e apresentado pelo Procurador.

Figura 2 - Lead de matéria jornalística que questiona o "discurso" da Justiça 


\section{Operação Lava Jato \\ Lula é denunciado pela força-tarefa da Lava Jato}

por Redação — publicado 14/09/2016 16h06, última modificação 14/09/2016 18h50

Procurador Deltan Dallagnol fala em "propinocracia" e diz que Lula é "comandante máximo do esquema de corrupção"

Fonte: www.cartacapital.com.br

Em ambos os exemplos, fica evidente a construção de um discurso jurídico baseado na utilização de termos impactantes que chegam à cena pública através da mídia, suscitando um intenso debate dentro e fora do ambiente midiático e, mais do que isso, fomentando uma luta pelo discurso legitimado que fornece sentido às questões jurídicas e uma visão parcial dos acontecimentos. O discurso mostra-se para além do teor jurídico de uma denúncia para alcançar a imagem de uma guerra do MPF contra uma enorme organização criminosa causadora de prejuízos ao interesse público brasileiro. Percebemos o discurso jurídico sendo operado com a linguagem e a lógica da mídia, procurando adaptar-se à esfera da visibilidade pública.

A seguir, buscamos elucidar, de maneira mais pontual, como se apresentam essas (re)configurações do campo jurídico à luz das lógicas midiáticas e dos entrelaçamentos entre o campo jurídico e o midiático na sociedade midiatizada.

\section{4 (Re)configurações do campo jurídico à luz da mídia}

Ao caracterizarmos o campo jurídico, é imperioso resgatar os estudos do sociólogo francês Pierre Bourdieu. Segundo Madeira (2007, p. 06), Bourdieu inclui a análise sobre 0 Direito dentro da sua teoria dos campos, utilizando "a teoria do habitus para explicar a ocupação de cargos jurídicos e as características e aspirações dos operadores do Direito".

Bourdieu (1989) adota a seguinte conceituação:

O campo jurídico é o lugar de concorrência pelo monopólio de dizer o direito, quer dizer, a boa distribuição (nomos) ou a boa ordem, no qual se defrontam agentes investidos de competência ao mesmo tempo social e técnica que consiste essencialmente na capacidade reconhecida de interpretar (de maneira mais ou menos livre ou autônoma) um corpus de textos que consagram a visão legítima, justa, do mundo social. É com esta condição que se podem dar as razões quer da autonomia relativa do 
direito, quer do efeito propriamente simbólico de desconhecimento, que resulta da ilusão da sua autonomia absoluta em relação às pressões externas (BOURDIEU, 1989, p. 212).

Nesta lógica, o autor entende que a ação jurídica está diretamente ligada ao poder, seja pela ocorrência dos profissionais da área, seja por meio daqueles que necessitam de justiça para defesa dos seus interesses. Concordamos com a ideia de Neto (2008) quando aponta que a noção de campo jurídico utilizada por Bourdieu é um importante instrumento para compreender o universo social do mundo jurídico, que acaba organizando as relações e delimita os espaços, onde os "operadores do Direito" concorrem entre si pelo monopólio do direito de dizer o Direito. Seria, nas palavras de Bourdieu (1986), "um ato de magia social”.

Madeira (2007) afirma que, entre os campos, sempre há uma interpenetração e existe uma relação entre o campo jurídico com os demais campos. Essa relação se dá na medida em que "há proximidade de interesses e afinidades dos habitus, ligados a formações familiares e escolares similares, o que favorece o parentesco das visões de mundo" (MADEIRA, 2007, p. 26). Nesse sentido, os campos sociais, segundo Bourdieu (2000), se entrelaçam ao campo midiático, ou seja, se unem por um fazer, uma estratégia ou elemento comum aos seus interesses e para que sejam vistos na esfera pública e cumprirem suas agendas e intenções junto aos demais campos.

Hoje, assistimos a este processo de entrelaçamento, especialmente ao redor dos processos de comunicação midiática, que, por sua vez, têm o poder de atingir um espectro grande de público, fazendo com que sejam visíveis e mobilizem a opinião pública no sentido de negociar demandas entre os diferentes campos e atores sociais, colocando-se na posição de mediador de processos e fenômenos de midiatização. Sobre os discursos dos campos sociais em tempos de midiatização, Fausto Neto (2007, p. 1) pontua que eles

[...] se manifestam através de complexas apropriações de operações midiáticas, redesenhando suas gramáticas e suas estratégias de reconhecimento manifestações complexas de operações de apropriação de características midiáticas, redesenhando suas gramáticas e suas estratégias de reconhecimento.

Segundo Sgorla (2009), os campos e atores sociais elaboram, estrategicamente, artifícios para ampliar a absorção das lógicas midiáticas, assumindo a gramática própria das mídias em suas conformações. 
Ao se apropriarem das lógicas midiáticas (mesmo que não abram mão de suas características específicas), os campos e atores sociais as utilizam para produzir novas estratégias de sobrevivência no 'espaço midiatizado', com a finalidade de obter visibilidade e ganhar relevância no tecido social (SGORLA, 2009, p. 66).

Na mesma linha de pensamento, Rodrigues (1997) assinala que os campos sociais necessitam dos media para praticar suas funções expressivas, marcando presença no espaço público e reconhecendo-o como lugar de visibilidade e notoriedade perante a sociedade.

Trata-se de uma verdadeira ascendência do campo midiático como um elemento integrador das relações que se estabelecem nos campos sociais, fazendo emergir fenômenos de midiatização, ou seja, colocando em primeiro plano a mídia, suas linguagens e estratégias. A mídia não é apenas importante na construção da percepção pública sobre o campo jurídico, mas tem um papel fundamental nas (re)configurações de suas lógicas e movimentos.

Tomemos como exemplo a Operação Lava Jato e a sua necessidade de legitimação perante a opinião pública. A visão da acusação ganhou rosto por meio da força-tarefa, em Curitiba, e seus discursos do bem contra o mal. Um valiosíssimo exemplo de que a posição que as instituições jurídicas ocupam e seus atores têm potencial para criar uma verdadeira guerra de verdades fabricadas, a partir da ideia de conferir verdade a algo ou transformar uma versão em fato. É opção por acusações midiáticas sem que tenha ainda havido uma condenação formal na esfera jurídica.

A Figura 3 apresenta matéria publicada no "Estadão" em que Teori Zavascki questionava, justamente, a utilização da mídia por parte do MPF para expor um discurso ambíguo e fundamentado apenas em uma lógica jurídica e na imagem de uma instituição que se corporifica na própria figura de procurador da República. Isso nos mostra como o discurso jurídico materializado pode convocar o direito de "fazer crer" pelo viés midiático.

Figura 3 - Notícia publicada em O Estado de S. Paulo, 04 outubro 2016

\section{Teori diz que procuradores da Lava Jato fizeram 'espetáculo midiático' em denúncia contra Lula}


Os desdobramentos da Lava Jato são tema de interesse público, portanto, próprios da democracia. Porém, a nosso ver, a operação inova nesse processo de aproximação entre o campo midiático e o campo jurídico ao se ancorar na mídia e assumir uma nova postura - a de um judiciário midiático. Esse "jogo" é maximizado pela inserção da tecnologia na sociedade, que acaba permeando diversos campos sociais. A midiatização acaba se tornando um processo que é próprio desta complexificação dos processos midiáticos. As novas tecnologias permitem um processo de comunicação em tempo real que torna acessível as formas de visibilidade (SODRÉ, 2002).

Assim,

[...] a sociedade contemporânea rege-se pela midiatização, quer dizer, 'pela tendência à virtualização' ou telerealização das relações humanas, presentes na articulação do múltiplo funcionamento institucional e de determinadas pautas individuais de conduta com as tecnologias da comunicação (SODRÉ, 2002, p. 21).

Ou seja, a mídia segue tendo um papel central na sociedade, agora não mais como mediadora, mas como uma "marca, modelo, matriz, racionalidade produtora e organizadora de sentido" (MATA, 1999, p. 84). O Campo dos Media situa-se em posição central na sociedade organizando a vida coletiva ao seu modo, sendo responsável pela produção dos sentidos e construindo a própria realidade social. Nesse sentido, ao campo dos media é delegado um papel de mediação entre os demais campos de uma sociedade, a ele é creditada uma legitimidade vicária; ou seja, os demais campos necessitam dos media para praticar suas funções expressivas, marcando sua presença no espaço público e, assim, reconhecem-no como o lugar de visibilidade e notoriedade perante a sociedade em que estão inseridos (RODRIGUES, 2000).

Do ponto de vista da mídia e da sociedade midiática, apoiamo-nos nas contribuições de Thompson (2008) que propõe um conjunto de questões acerca do processo midiático e seus impactos na sociedade. As lógicas e protocolos midiáticos acabam sendo incorporados à prática de diversos campos sociais, promovendo novas formas de sociabilidade, novas formas de ser e de estar presente no mundo, tendo a mídia como matriz e referência.

No contexto do campo jurídico, a mídia apresenta-se como um elemento que possibilita a conquista de visibilidade na sociedade e, ao invés de suporte, passa a ser um ator do processo comunicacional. Ela transforma uma acusação, fora da arena 
processual, em uma verdade plena, colocando os acusados, seus defensores e críticos no mal que precisa ser combatido a todo custo. $O$ atual protagonismo das ações do campo jurídico se deve, justamente, por esse imbricamento com o campo midiático. As fronteiras entre esses dois campos desaparecem e eles se tornam um mesmo espaço que movimenta temas centrais da democracia, caros à sociedade, em torno da visibilidade, legitimidade e credibilidade.

\section{Considerações Finais}

As reflexões promovidas até aqui tiveram como objetivo observar as (re)configurações do campo jurídico e suas movimentações na sociedade contemporânea, colocando-as à luz dos processos de midiatização.

Com base no fio teórico apresentado, podemos ponderar algumas questões que envolvem a mídia enquanto mediadora dos demais campos sociais - compreendemos, porém, que hoje ela enquadra-se como matriz e os campos sociais se ajustam a esta configuração. Pensando no entrelaçamento entre o campo jurídico e o campo midiático, não há como negar que a midiatização é o resultado desses entrelaçamentos entre a mídia e as instituições que moldam as interações sociais, reconfigurando as práticas dos campos sociais, notadamente na arena processual.

Acionamos, novamente, Fausto Neto (2006) que observa que as operações de midiatização se tornam habilidades estratégicas para que determinados discursos conquistem visibilidade social. Uma nova rotina no contexto midiatizado passa a ser a principal tática para a publicização dos campos sociais e dos atores jurídicos e seus objetivos institucionais e processuais.

No âmbito do campo jurídico, esta lógica é perceptível na medida em que ele se entrelaça ao campo midiático, organiza estratégias e artifícios para maximizar absorção de suas demandas pela mídia. Ao fazer essa apropriação das lógicas midiáticas o campo jurídico e seus atores sobrevivem no espaço midiatizado, ganham visibilidade e relevância (re)configurando-se à luz da mídia.

\section{REFERÊNCIAS}


BARBERO, J. M. Dos meios às mediações: comunicação, cultura e hegemonia. Rio de Janeiro: UFRJ, 1997.

BOURDIEU, P. La force du dutroit: Éléments pour une sociologie du champ juridique. Paris: Actes de la recherche em sciences sociales, 1986.

BOURDIEU, P. O poder simbólico. Rio de Janeiro: Bertrand, 1989.

BOURDIEU, P. Poder, derecho y classes sociales. Bilbão: Editorial Desclée de Brouwer, 2000.

BOURDIEU, P.; TEUBNER, G. La fuerza del derecho. Bogotá: Uniandes, 2000.

BRAGA, J. L. Os estudos de interface como espaço de construção do Campo da Comunicação. Revista Contracampo, n. 10/11, 2004.

BRAGA, J. L. Constituição do campo da comunicação. Verso e Reverso, v. 25, n. 58, janabr 2011.

BRAGA, J. L. et al. (org.). 10 perguntas para a produção de conhecimento em comunicação. São Leopoldo: Unisinos, 2013.

CARTACAPITAL. Lula é denunciado pela força-tarefa da Lava Jato. CartaCapital, 14 set. 2016 [online]. Disponível em: http://www.cartacapital.com.br/politica/lula-e-denunciadolava-jato. Acesso em: 15 nov. 2016.

FAUSTO NETO, A. Midiatização, prática social: prática de sentido. In: ENCONTRO ANUAL DA ASSOCIAÇÃO NACIONAL DOS PROGRAMAS DE PÓS-GRADUAÇÃO EM COMUNICAÇÃO. Compós, 15, 2006, Bauru. Anais eletrônicos. Disponível em: http://docslide.com.br/education/midiatizacao-pratica-social-pratica-de-sentido-de-antoniofausto-neto.html. Acesso em: 15 nov. 2016.

FAUSTO NETO, A. Enunciação, auto-referencialidade e incompletude. Revista Famecos, Porto Alegre, n. 34, dez. 2007.

FOSSÁ, M. I.; KEGLER, J. Q. Da sociedade midiática à sociedade midiatizada: a complexificação da ambiência organizacional. In: DUARTE, E. B.; CASTRO, M. L. D. de (org.). Em torno das mídias: práticas e ambiências. Porto Alegre: Sulina, 2008.

G1.GLOBO. Afinal, procurador da Lava Jato disse 'não temos prova, temos convicção'? G1.Globo, 16 set. 2016 [online]. Disponível em: http://g1.globo.com/politica/operacaolava-jato/noticia/2016/09/afinal-procurador-da-lava-jato-disse-nao-temos-prova-temosconviccao.html. Acesso em: 15 nov. 2016.

HJARVARD, S. A midiatização da cultura e da sociedade. São Leopoldo: Unisinos, 2014.

LAKATOS, E. M.; MARCONI, M. de A. Fundamentos de metodologia científica. São Paulo: Atlas, 2006. 
LINDNER, J.; MOURA, R. M. Teori diz que procuradores da Lava Jato fizeram 'espetáculo midiático' em denúncia contra Lula. O Estado de S. Paulo, 04 out. 2016 [online].

Disponível em: http://politica.estadao.com.br/noticias/geral,teori-diz-que-procuradores-dalava-jato-fizeram-espetaculo-midiatico-em-denuncia-contra-lula,10000080176. Acesso em: 15 nov. 2016.

MADEIRA, L. M. O Direito das Teorias Sociológicas de Pierre Bourdieu e Niklas Luhmann. Direito \& Justiça, Revista de Direito da PUCRS. Porto Alegre, v. 33, n. 1, p. 19-39, 2007.

MATA, M. C. De la cultura massiva a la cultura mediática. Diálogos de la comunicación, n. 56, 1999.

MARTINO, L. M. S. Mídia e poder simbólico. São Paulo: Paulus, 2003.

NETO, J. S. O campo jurídico em Pierre Bourdieu: a produção de uma verdade a partir da noção de propriedade privada nos manuais de Direito. Revista Sequência, n 16, p.83100, 2008.

PÉRSIGO, P.; FOSSÁ, I. Da Sociedade Midiática à Midiatizada: uma atualização da comunicação organizacional. In: Intercom - Sociedade Brasileira de Estudos Interdisciplinares da Comunicação, XI Congresso de Ciências da Comunicação na Região Sul. Novo Hamburgo, 17-19 mai. 2010.

RODRIGUES, A. D. Estratégias da comunicação. Lisboa: Presença, 1997.

RODRIGUES, A. D. A gênese do campo dos media. In: SANTANA, R. N. (org.).

Reflexões sobre o mundo contemporâneo. Teresina: Renan, 2000.

SFEZ, L. Critique de la décision. Paris: Presse de la FNSP, 1992.

SGORLA, F. A Visibilidade Midiática: da sociedade midiática à sociedade midiatizada. Tecer (Belo Horizonte), v. 9, p. 1-10, 2009.

SILVERSTONE, R. A textura da experiência. In: Por que estudar a mídia? São Paulo: Loyola, 2003.

SODRÉ, M. Antropológica do espelho: uma teoria da comunicação linear em rede. 6 . ed. Rio de Janeiro: Vozes, 2002.

SODRÉ, M. Comunicação: um campo em apuros teóricos. Matrizes, São Paulo, ano 5, n. 2, jan.-jun., p. 11-27, 2012.

THOMPSON, J. B. Ideologia e cultura moderna. Petrópolis: Vozes, 1990.

THOMPSON, J. B. A mídia e a modernidade: uma teoria social da mídia. Petrópolis: Vozes, 2008.

\section{NOTAS}

TÍTULO DA OBRA 
As (re)configurações do campo jurídico e sua relação com a mídia na sociedade contemporânea.

\section{Charlene Dalcol}

Doutoranda no Programa de Pós-Graduação em Comunicação da Universidade Federal de Santa Maria (UFSM).

charlenedalcol@gmail.com

(1) https://orcid.org/0000-0002-0982-4116

\section{Maria Ivete Trevisan Fossá}

Doutora em Administração pela Universidade Federal do Rio Grande do Sul (UFRGS);

Professora Associada nível II do Departamento de Ciências da Comunicação da Universidade Federal de Santa Maria (UFSM).

fossa@terra.com.br

(D) https://orcid.org/0000-0001-6536-6714

\section{Endereço de correspondência do principal autor}

Força Aérea Brasileira, Guarnição de Aeronáutica de Santa Maria.

RSC 287

Camobi

97105910 - Santa Maria, RS - Brasil - Caixa-postal: 341

Telefone: (55) 32203311

Ramal: 3310

\section{FINANCIAMENTO}

Não se aplica.

\section{CONFLITO DE INTERESSES}

Não se aplica.

\section{LICENÇA DE USO}

Os autores cedem à Em Tese os direitos exclusivos de primeira publicação, com o trabalho simultaneamente licenciado sob a Licença Creative Commons Attribution 4.0 Internacional (CC BY). Estra licença permite que terceiros remixem, adaptem e criem a partir do trabalho publicado, atribuindo o devido crédito de autoria e publicação inicial neste periódico. Os autores têm autorização para assumir contratos adicionais separadamente, para distribuição não exclusiva da versão do trabalho publicada neste periódico (ex.: publicar em repositório institucional, em site pessoal, publicar uma tradução, ou como capítulo de livro), com reconhecimento de autoria e publicação inicial neste periódico.

\section{PUBLISHER}

Universidade Federal de Santa Catarina. Programa de Pós-Graduação em Sociologia Política. Publicado no Portal de Periódicos UFSC. As ideias expressadas neste artigo são de responsabilidade de seus autores, não representando, necessariamente, a opinião dos editores ou da universidade.

\section{HISTÓRICO}

Recebido em: 19 de março de 2017

Aprovado em: 29 de agosto de 2017 